\title{
Utilização Do Modelo Do PCM Para A Inclusão Do Efeito Do Solvente No Estudo De Propriedades Magnéticas De Polifenóis
}

*Agnes Jalowitzki Silva ${ }^{1}$ (PG), Thais Forest Giacomello ${ }^{2}$ (PG), Fabio Luiz Paranhos da $\operatorname{Costa}^{3}$ (PQ).

${ }^{1}$ Universidade Federal de Jataí: agnesjalowitzki@ gmail.com

${ }^{2}$ Universidade Federal de Jataí: thaisgiaco@gmail.com

${ }^{3}$ Universidade Federal de Jataí: fabbioquimica@gmail.com

Palavras-chave: polifenóis, chalconas, RMN, modelo PCN.

Estudos epidemiológicos demonstraram claramente que as dietas ricas em alimentos vegetais protegem os seres humanos contra doenças degenerativas, como câncer e doenças cardiovasculares. Os alimentos vegetais contêm fibras, vitaminas, fitosteróis, compostos de enxofre, carotenóides e ácidos orgânicos, que contribuem para os efeitos sobre a saúde, mas também contêm grande variedade de polifenóis, que são cada vez mais considerados como agentes protetores eficazes [1-2]. Estes compostos são um dos mais importantes e certamente os mais numerosos entre os grupos de fitoquímicos presentes no reino vegetal, como por exemplo, chalconas, curcuminas, ácidos fenólicos, estilbenos etc [3]. Os derivados de chalconas são encontrados amplamente em produtos naturais [4]. Esta classe de compostos é considerada precursora chave para a síntese de flavonoides e isoflavonoides [4]. Eles têm várias atividades biológicas, incluindo antiinflamatório, anti-leishmania, antimicótico e antiviral, são alguns exemplos de sua ampla gama de ação, etc. [4].

Neste trabalho é apresentado o desenvolvimento de um protocolo para determinação de deslocamento químico $(\delta)$ de ${ }^{13} \mathrm{C}$ utilizando um conjunto de 20 chalconas (totalizando mais de 300 deslocamentos químicos, $\delta$ ) com diferentes padrões de substituição, cujas estruturas foram elucidadas na literatura [7-8].

Os cálculos de otimização de geometria e de frequência vibracional foram realizados em nível mPW1PW91/6-31G(d), em fase gasosa. Já as constantes de proteção magnética isotrópicas $(\sigma)$ foram obtidas em fase gasosa e levando-se em conta os efeitos do solvente utilizando a base 6-31G(d). Para tanto utilizou-se o modelo do PCM (Polarizable Continuum Model) [5]. Os deslocamentos químicos ( $\delta$ ) calculados foram usados para gerar dois fatores de escalonamento baseados em regressões lineares, uma em fase gasosa e um em fase líquida (solvente clorfórmio). Os fatores de escalonamento foram gerados utilizando-se o programa Origin 8.0 plotando-se os 
valores de deslocamento químicos calculados $\left(\delta_{\text {calc }}\right)$ pelos deslocamentos químicos experimentais do conjunto de chalconas. Deste modo, os valores do coeficiente angular (a) e coeficiente linear (b) obtidos a partir dessa regressão linear podem ser usados para gerar deslocamentos químicos escalonados $\left(\delta_{\text {scal }}\right)$, usando a expressão $\delta_{\text {scal }}=a \cdot \delta_{\text {calc }} \pm b$ (1). Assim, referente ao conjunto de 20 chalconas, foi gerada uma equação uma equação na fase líquida, $\delta_{\text {scal }}=1,04$. $\delta_{\text {cal }}-2,15, \mathrm{r}^{2}=0,99024$. Todos os cálculos quânticos foram realizados com o pacote de software Gaussian 09 [6]. Para o conjunto de chalconas, o Desvio Médio Absoluto (MAD) e o Desvio Quadrático Médio da Raiz (RMSD), em ppm, antes e depois (entre parênteses), a aplicação da equação (1) na fase líquida obteve-se: MAD $=5,33(3,62)$ e RMS $=6,83(5,24)$. Considerando um conjunto de 20 chalconas com diferentes padrões de substituição, foi desenvolvido um protocolo parametrizado para o cálculo de ${ }^{13} \mathrm{C}$ utilizando a técnica computacional de $\mathrm{RMN}$ dos deslocamentos químicos das chalconas de acordo com o nível de teoria e a base apresentadas.

\section{Referências}

1. C. Manach; G. Williamson; C. Morand; A. Scalbert; C. Rémésy, Bioavailability and bioefficacy of polyphenols in humans. The American journal of clinical nutrition. 230, 242 (2005).

2. A. Scalbert; G. Williamson. Dietary intake and bioavailability of polyphenols. The Journal of nutrition. 2073, 2085 (2000).

3. N. R. Perron; J. L. Brumaghim, Cell Biochem. Biophys. 53, 75 (2009).

4. P. Singh; A. Anand; V. Kumar, Eur. J. Med. Chem. 85, 758 (2014).

5. J. Pliego Jr. Modelos contínuos do solvente: fundamentos. Química Nova. 535, 542 (2006).

6. A. E. Frisch; M. J. Frisch; G. Trucks, Gaussian 09, Revision D.01, User's Reference, Gaussian Inc., Pittsburgh, USA (2009).

7. F. L. P. Costa, P. F. Gomes; A. K. Silva; L. M. Lião, J. Braz. Chem. Soc. 00, 1-6 (doi:10.21577/0103-5053.20170062) (2017).

8. P. K.Agrawal, "Carbon-13 NMR of Flavonoids. Studies in Organic Chemistry, v. 34” (1989), Elsevier, Amsterdan. The Netherlands.Reference, Gaussian Inc., Pittsburgh, USA (2009). 